\title{
For James Stark
}

Chaney, Anthony, Runaway: Gregory Bateson, the Double Bind, and the Rise of Ecological Consciousness. Chapel Hill, NC: University of North Carolina Press, 2017. Pp. 304. ISBN 978-1-4696-3173-8. \$32.95 (cloth cover).

Gregory Bateson presents a challenging subject for biographers and historians. He was famously sceptical of the conventional ideas of mind and self that serve as the foundation stones of biography yet at the same time the shape of his life is all too well known. The son of the pioneer geneticist, William Bateson, he abandoned an early enthusiasm for natural history in favour of anthropology. Supported by his Cambridge tutor, A. C. Haddon, he carried out fieldwork, first among the Baining and Sulka peoples of New Britain and then more rewardingly among the latmul tribe of Papua New Guinea. Here, he met and fell in love with Margaret Mead, and would soon take on and share her enthusiasm for a culturalist approach in anthropology. Following the example of Ruth Benedict and Franz Boas they strove to overcome the lazy ethnocentrism that had characterised early studies of indigenous peoples, attempting instead to judge their subjects' belief and actions on their own terms.

Bateson's newfound commitment to cultural relativism was reinforced by an Anglo-Saxon scepticism toward the working concepts of philosophy and natural science: a scepticism drawn from the writings of Samuel Butler, Bertrand Russell, Alfred North Whitehead and R. G. Collingwood. As a result his one major work of ethnography, Naven (1936), ostensibly a study of latmul (a kind of carnivalesque kinship ritual), became an exercise in anthropological selfcritique. In an attempt to overcome the fallacy of 'misplaced concreteness' that turned the working categories of early twentieth-century ethnological investigation into social facts, Bateson elaborated a new tentative vocabulary built up from loan words and neologisms such as 'ethos', 'eidos' and 'schismogenesis', to explore how the categories groups lived by were the contingent and practical outcome of dynamic social relationships. An attempt to explain latmul ritual became, instead, a meditation on the nature of explanation. The defining feature of all Bateson's investigations - from his anthropological fieldwork to his post war research on schizophrenic behaviour and dolphin communication - was his insistence that these subjects serve to illuminate the unacknowledged assumptions that organise our own patterns of thought.

The great strength of Bateson's approach, with its emphasis on the mutability of concepts, was that it opened itself up to reinvention. By the 1950s, Naven could be read as a prototypical exercise in systems theory. Bateson and Mead were both drawn towards cybernetics, participating in the early Macy Conferences. Bateson found in the new science a potent means for understanding the process of abstraction, seeing in the shifting levels of information exchange (from signal to sign to context) a parallel to the different levels of interaction he had tried to map out in his study of latmul culture. From the 1940s onwards, Bateson combined this idea of orders of communication with a keen awareness of the ways that signals could feed back and feed forwards to create vicious circles of repetitive behaviour or open up new patterns of learning and new levels of perspective. It is this Bateson, committed to an ongoing critique of mindless mechanism and aware of how everyday frustrations might drive us toward a transcendental awareness, that appears as the hero of Chaney's Runaway. 
For much of Runaway, Bateson appears as a kind of countercultural guru, performing before cross-legged audiences of uncomprehending beatniks as he attempts to apply communications theory to the analysis of the cold war's cultural malaise. Bateson appears at the Two Worlds Conference in Sacramento in 1966 and, more famously, with Allen Ginsberg at the Dialectics of Liberation Conference organised by the radical psychiatrists, R. D. Laing and David Cooper at the Camden Roundhouse in 1967. In front of these audiences, Bateson's investigations into levels of meaning and abstraction were reframed as call to radical action. As he made clear: "the Question is not what is the best thing to do within the rules as they are at the moment. The question is how can we get away from the rules from within which we have been operating." (Chaney, 154). Bateson's long years of fieldwork with alien forms of communication (in anthropology, psychiatry and animal training) held out the promise that one could escape the cold war samsara of constant closed loops of repetitive behaviour. In its place he offered an ecological vision of consciousness in which the individual recognised the contingent and mutable nature of the games they were playing and the materials they played them.

Parts of this story are familiar, John Brockman and Andy Pickering have both already offered detailed readings of the radical impact of Bateson's thought, and his philosophy has received more detailed reconstructions (in excellent works by David Lipset and Peter Harries-Jones), Chaney however brings something new to these discussions through his pursuit of the rather Batesonian strategy of drawing readers' attention to the multiple contexts that sustained Bateson's ideas. Whereas other authors have looked to Wiener and Mead as formative influences, BJHS readers will probably be pleased to discover in Chaney's work a careful emphasis on Bateson's interest in Lamarckism; partly 'inherited' from his father but reworked through correspondence with the historians of science, William Coleman and Charles Coulton Gillispie. The Lamarck fashioned in these conversations was an individual who had redescribed the universe: it was no longer an ordered hierarchy but a shifting assemblage driven by change from below. There were no fixed points. As with the universe so with the mind. As Bateson told his audience at the Roundhouse: "I am inclined to regard the total systemic creature, you see, as mind, and the total systemic ecology as mind, and the culture as mind" (218) It's a point of view which explodes the possibility of biography, allowing many different biographies to be told at many different levels. And its point of view which encourages reflexivity. Writing to Coleman in the early 1960s, Bateson agreed that the the history of science is only superficially guided by scientific research and disciplined thinking. "Behind this superficial facade", he claimed, "there is always, a 'heaving mass of inchoate mysticism which scientific figures never put into words'"(115) He recalled how as a student at Trinity he had been shown Newton's 'alchemistic manuscripts, deistic tracts and other occult materials' locked up in a 'big wooden box' and asked, rhetorically, 'Do historians have no such boxes?' They clearly do, and it is to Chaney's credit that he makes no attempt to disguise to his commitment to Bateson's vision of an ecological consciousness and to the political reformation that would be won through its acceptance. His approach and Bateson's arguments remain provocative, calling into question the assumption of a fixed context that is usually evoked to ground socio-historical narratives. As Bateson and Chaney make clear, fixing a context is as much an achievement as fixing an identity. This is not a definitive Bateson biography, and it certainly won't be the final word on Bateson, but Chaney's achievement is to show how this provisionality is a strength.

Rhodri Hayward

Queen Mary University of London 